\title{
Impact of initial respiratory compliance in ventilated patients with acute respiratory distress syndrome related to COVID-19
}

\author{
Florent Laverdure ${ }^{1 *}$ (D, Amélie Delaporte ${ }^{1}$, Astrid Bouteau ${ }^{1}$, Thibaut Genty ${ }^{1}$, François Decailliot ${ }^{2}$ and \\ François Stéphan ${ }^{1}$
}

Keywords: COVID-19, Acute respiratory distress syndrome, Invasive mechanical ventilation, Respiratory compliance, Prone positioning, Positive end-expiratory pressure

Dear Editor,

Coronavirus disease 2019 (COVID-19) is associated with a high fatality rate in patients requiring invasive mechanical ventilation (IMV) [1]. COVID-19-related acute respiratory distress syndrome (COVID-ARDS) might exhibit vascular insults, resulting in loss of hypoxic pulmonary vasoconstriction, and subsequent dissociation between profound hypoxemia and preserved static compliance of the respiratory system (Cst-rs) [2]. Experts recently distinguished two phenotypes of COVID-ARDS according to their Cst-rs [2]: patients were classified as groups L (low elastance (or high Cst-rs) and low recruitability) and $\mathrm{H}$ (high elastance and high recruitability). They recommended different ventilatory approaches [3], contrary to Sepsis Surviving Campaign guidelines [4]. We describe characteristics and outcomes in patients with different initial Cst-rs, but all receiving IMV following ARDS guidelines.

We report the courses of respiratory parameters and outcomes in an observational cohort of 36 patients who developed COVID-ARDS requiring IMV from March 17 to April 18, 2020. Patients were divided into two groups (low and high Cst-rs) according to their initial Cst-rs was above or below the median value. We applied institutional ARDS procedures to all patients. Our management was based on the systematic use of neuromuscular blockers for at least $48 \mathrm{~h}$, positive end-expiratory pressures (PEEP) titrated on oxygenation, and prone positioning sessions if $\mathrm{PaO}_{2} / \mathrm{FiO}_{2}$ ratio dropped below 150. Patients' data were analyzed until patients were discharged from the intensive care unit or died. Courses of Cst-rs, PEEP, and tidal volumes were analyzed using a linear mixed model.

The median baseline Cst-rs was $36 \mathrm{~mL} / \mathrm{cmH}_{2} \mathrm{O}$ [interquartile range (IQR) 29-44]. Characteristics of the patients at baseline, therapeutic interventions, and outcome measures are provided in Table 1 . Twenty-nine patients (80.6\%) in whom $\mathrm{PaO}_{2} / \mathrm{FiO}_{2}$ ratio dropped below 150 were placed in prone position. Courses of Cst-rs, PEEP levels, and tidal volumes are provided in Fig. 1. Cst-rs did not vary over time in both groups and remained higher in the high Cst-rs group (mean difference $17.7 \mathrm{~mL} /$ $\mathrm{cmH}_{2} \mathrm{O}[95 \%$ CI 11.3-24.0] compared to the low

* Correspondence: f.laverdure@hml.fr

'Department of Anesthesiology and Intensive Care, Hôpital Marie Lannelongue, Groupe Hospitalier Paris Saint Joseph, Paris, France

Full list of author information is available at the end of the article 
Table 1 Baseline characteristics, therapeutic interventions, and outcomes of patients, according to respiratory compliance

\begin{tabular}{|c|c|c|c|c|}
\hline & $\begin{array}{l}\text { Overall }(\boldsymbol{N}=36), \\
\text { no. (\%) of patients }{ }^{\text {a }}\end{array}$ & $\begin{array}{l}\text { High respiratory } \\
\text { compliance }(\boldsymbol{N}=17) \text {, } \\
\text { no. (\%) of patients }\end{array}$ & $\begin{array}{l}\text { Low respiratory } \\
\text { compliance }(\boldsymbol{N}=19) \text {, } \\
\text { no. }(\%) \text { of patients }\end{array}$ & $\begin{array}{l}\boldsymbol{P} \text { value } \\
\text { between } \\
\text { groups }\end{array}$ \\
\hline \multicolumn{5}{|l|}{ Baseline characteristics } \\
\hline Age, mean $\pm S D$, years & $53.4 \pm 10.2$ & $56.1 \pm 7.1$ & $50.9 \pm 12.1$ & 0.12 \\
\hline Male sex & $30(83.3)$ & $16(94.1)$ & $14(73.7)$ & 0.18 \\
\hline Obesity $^{b}$ & $14(38.9)$ & $3(17.7)$ & $11(57.9)$ & 0.02 \\
\hline Diabetes mellitus & $11(30.6)$ & $5(29.4)$ & $6(31.6)$ & 1.0 \\
\hline Arterial hypertension & $16(44.4)$ & $11(64.7)$ & $5(26.3)$ & 0.19 \\
\hline SAPS 2 score, median [IQR] & $31[27-36]$ & $31[29-36]$ & 29 [22-39] & 0.51 \\
\hline SOFA score, median [IQR] & $5[4-7]$ & $6[4-7]$ & $4[3-6]$ & 0.04 \\
\hline Tidal volume, mean $\pm \mathrm{SD}, \mathrm{mL} / \mathrm{kg}$ & $6.1 \pm 0.6$ & $6.2 \pm 0.3$ & $6.0 \pm 0.7$ & 0.02 \\
\hline Respiratory frequency, median [IQR], breaths/min & $25[24-27]$ & $25[24-26]$ & $26[24-28]$ & 0.64 \\
\hline $\mathrm{FiO}_{2}$, median $[\mathrm{IQR}], \%$ & $65[50-100]$ & $60[40-80]$ & $70[60-100]$ & 0.07 \\
\hline $\mathrm{PaO}_{2} / \mathrm{FiO}_{2}$ ratio, median $[\mathrm{IQR}]$ & 152 [112-240] & $209[150-256]$ & $117[83-201]$ & 0.02 \\
\hline $\mathrm{PEEP}$, mean $\pm \mathrm{SD}, \mathrm{CmH}_{2} \mathrm{O}$ & $13.4 \pm 3.2$ & $13.4 \pm 3.6$ & $13.4 \pm 3.1$ & 0.92 \\
\hline Respiratory compliance, mean $\pm \mathrm{SD}, \mathrm{mL} / \mathrm{cmH}_{2} \mathrm{O}^{c}$ & $39.4 \pm 16.9$ & $51.8 \pm 16.4$ & $28.3 \pm 6.1$ & \\
\hline \multicolumn{5}{|l|}{ Therapeutic interventions } \\
\hline Prone positioning & $29(80.6)$ & $12(70.6)$ & $17(89.5)$ & 0.22 \\
\hline Number of sessions, median [IQR] & $4.0[2.0-6.0]$ & $4.0[2.5-5.0]$ & $5.0[1.7-6.0]$ & 0.91 \\
\hline Inhaled nitric oxide & $9(25.0)$ & $2(11.8)$ & $7(36.8)$ & 0.13 \\
\hline Venovenous ECMO & $7(19.4)$ & $0(0.0)$ & $7(36.8)$ & 0.008 \\
\hline Vasopressors & $31(86.1)$ & $17(100.0)$ & $14(73.7)$ & 0.048 \\
\hline Renal replacement therapy & $7(19.4)$ & $3(17.7)$ & $4(21.1)$ & 1.0 \\
\hline Hydroxychloroquine & $32(88.9)$ & $16(94.1)$ & $16(84.2)$ & 0.6 \\
\hline Steroïds & $11(30.6)$ & $5(29.4)$ & $6(31.6)$ & 1.0 \\
\hline \multicolumn{5}{|l|}{ Outcomes } \\
\hline Ventilator-free days, median [IQR] & $3.0[0.0-14.5]$ & $10.0[0.0-17.2]$ & $0.0[0.0-8.0]$ & 0.04 \\
\hline Mortality at day 28 & $4(11.1)$ & $1(5.9)$ & $3(15.8)$ & 0.61 \\
\hline
\end{tabular}

Abbreviations: $E C M O$ extracorporeal membrane oxygenation, $\mathrm{FiO}_{2}$ fraction of inspired oxygen, $P E E P$ positive end-expiratory pressure

anless otherwise indicated

${ }^{b}$ Obesity is defined by a body mass index above $30 \mathrm{~kg} / \mathrm{m}^{2}$. The formula for body mass index is weight in kilograms divided by height in meters squared

'No statistical comparison performed

Cst-rs group, $P<0.001)$. Tidal volumes were higher in the high Cst-rs group (mean difference $0.90 \mathrm{~mL} /$ $\mathrm{kg}$ [95\% CI 0.31-1.50] compared to the low Cst-rs group, $P=0.005)$. PEEP levels were not different between groups and decreased over time.

On day 28, 32 patients (88.9\%) survived and 25 (69.4\%) were discharged from the intensive care unit. As of May 30, 2020, weaning from mechanical ventilation was effective in 16 high Cst-rs patients (94.1\%) and 13 low Cst-rs patients $(68.4 \%)(P=0.09)$.

As previously suggested [3], some COVID-ARDS patients exhibit high initial Cst-rs. However, the median baseline Cst-rs was not different from Cstrs observed in "typical" non-COVID-ARDS, as demonstrated in another study [5]. The high Cst-rs did not drop and remained different from the initial low Cst-rs during the first 28 days, suggesting a lack of transition from a high to a low Cst-rs phenotype in patients receiving neuromuscular blockers. We therefore hypothesize that if this transition exists, self-inflicted lung injury during spontaneous ventilation or asynchronies is one of its main determinants.

Although therapeutic management of low Cst-rs patients is not disputed $[2,6]$, a low-PEEP, high- $-\mathrm{FiO}_{2}$, liberal tidal volume approach has been suggested for high Cst-rs patients. Using established ARDS therapies [3] with either low or high Cst-rs, the survival rate is better 


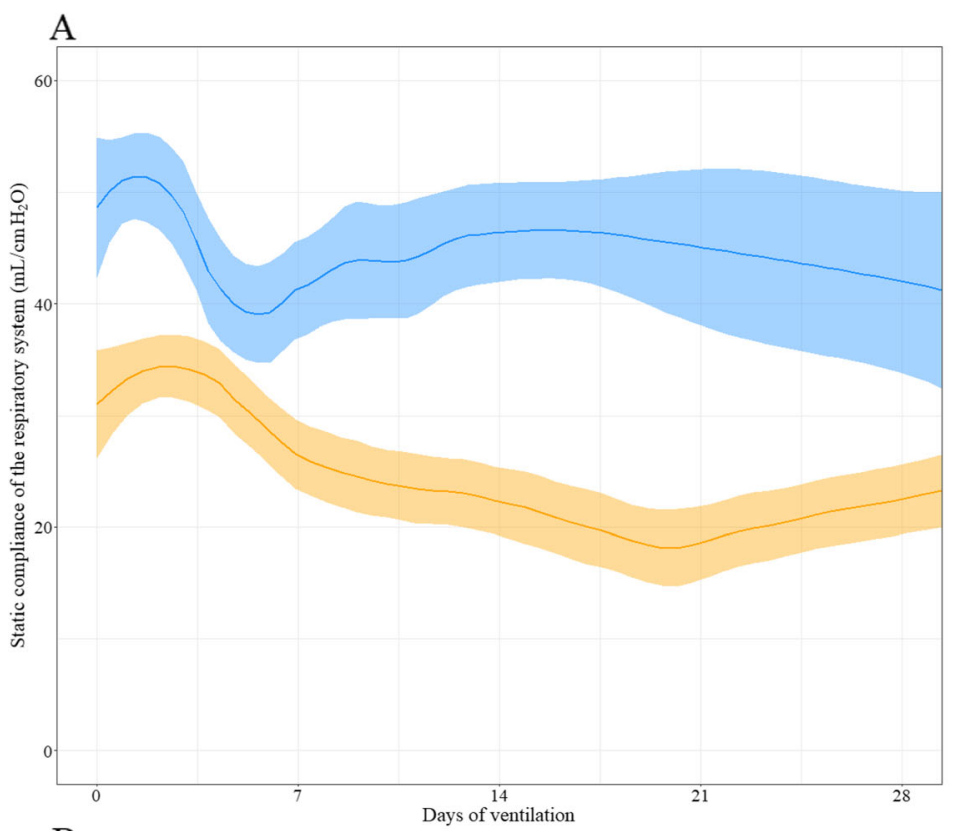

$\mathrm{B}$

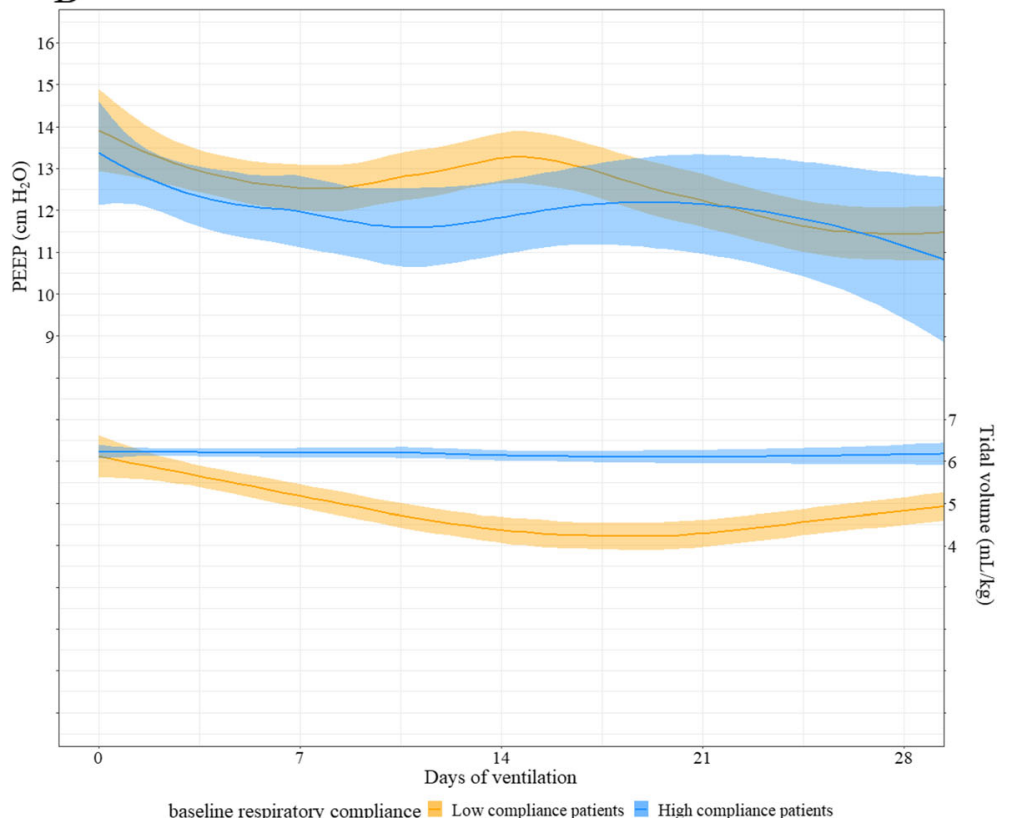

Fig. 1 Course of the respiratory system static compliances (Cst-rs), positive end-expiratory pressures (PEEP), and tidal volumes (Vt). The means and 95\% confidence intervals are represented respectively by solid lines and colored areas. Results are expressed in mean differences $[95 \% \mathrm{Cl}]$. a Cst-rs remained higher in the high initial Cst-rs group. There was no significant effect of time on Cst-rs (slope $=-$ $0.03 \mathrm{~mL} / \mathrm{cmH}_{2} \mathrm{O} /$ day of ventilation $[95 \% \mathrm{Cl}-0.17$ to 0.12$], P=0.70$ ). b PEEP levels did not differ between groups (high vs. low Cst-rs group $-0.69 \mathrm{cmH}_{2} \mathrm{O}[95 \% \mathrm{Cl}-2.05$ to 0.66$\left.], P=0.33\right)$. There was a statistically significant effect of time on $\mathrm{PEEP}\left(\mathrm{slope}=-0.10 \mathrm{cmH} \mathrm{C}_{2} \mathrm{O} /\right.$ day of ventilation $[95 \% \mathrm{Cl}-0.13$ to -0.06$], P<0.001)$. Vt were higher in the high Cst-rs group. There was no significant effect of time on Vt (slope $=-0.006[-0.02$ to 0.007$], P=0.375$ )

than initially reported [1], following a recent publication using the same strategy [5]. A low initial Cst-rs could be a marker of severity, as suggested by more extracorporeal membrane oxygenation requirement and less ventilator-free days at day 28 .
Limitations include the small number of patients and the retrospective design. While further study is needed, our findings provide arguments to treat all COVID-ARDS with established ARDS therapies, whatever the initial value of Cst-rs. 


\section{Abbreviations}

ARDS: Acute respiratory distress syndrome; COVID-19: Coronavirus disease 2019; Cst-rs: Static compliance of the respiratory system; IMV: Invasive mechanical ventilation; PEEP: Positive end-expiratory pressure

\section{Acknowledgements}

We thank all clinical and nursing staff of Marie Lannelongue Hospital for their flawless commitment during this outbreak. We also thank Sebastien Morisset, MSC, for performing the statistical analysis, and Vincent Roth, MD (Easy $\mathrm{CRF} \mathrm{SAS}{ }^{\oplus}$ ), for providing us the database.

\section{Authors' contributions}

FL and FS have designed the work. All authors have drafted the work. All authors have made the acquisition, analysis, and interpretation of the data. All contributors read and approved the manuscript.

\section{Funding}

The present study was supported solely by institutional sources.

\section{Availability of data and materials}

The datasets used and analyzed during the current study are available from the corresponding author on reasonable request.

\section{Ethics approval and consent to participate}

The entire project was approved by the Groupe Hospitalier Paris Saint Joseph Ethics Board (IRB 00012157. Project number: 20-37816004), which waived informed consent.

\section{Consent for publication}

Not applicable

\section{Competing interests}

The authors declare that they have no competing interests.

\section{Author details}

${ }^{1}$ Department of Anesthesiology and Intensive Care, Hôpital Marie Lannelongue, Groupe Hospitalier Paris Saint Joseph, Paris, France. ${ }^{2}$ Pediatric Intensive Care Unit, Hôpital Marie Lannelongue, Groupe Hospitalier Paris Saint Joseph, Paris, France.

Received: 3 June 2020 Accepted: 1 July 2020

Published online: 09 July 2020

\section{References}

1. Richardson S, Hirsch JS, Narasimhan M, Crawford JM, McGinn T, Davidson $\mathrm{KW}$, et al. Presenting characteristics, comorbidities, and outcomes among 5700 patients hospitalized with COVID-19 in the New York City area. JAMA. 2020;323:20 https://doi.org/10.1001/jama.2020.6775.

2. Gattinoni L, Chiumello D, Rossi S. COVID-19 pneumonia: ARDS or not? Crit Care. 2020;24:154 https://doi.org/10.1186/s13054-020-02880-z.

3. Marini JJ, Gattinoni L. Management of COVID-19 respiratory distress. JAMA. 2020; https://doi.org/10.1001/jama.2020.6825.

4. Alhazzani W, Møller MH, Arabi YM, Loeb M, Gong MN, Fan E, et al. Surviving Sepsis campaign: guidelines on the management of critically ill adults with coronavirus disease 2019 (COVID-19). Intensive Care Med. 2020. https://doi. org/10.1097/CCM.0000000000004363.

5. Haudebourg A-F, Perier F, Tuffet S, de Prost N, Razazi K, Mekontso Dessap A, et al. Respiratory mechanics of COVID-19 vs. non-COVID-19 associated acute respiratory distress syndrome. Am J Respir Crit Care Med. 2020. https://doi. org/10.1164/rccm.202004-1226LE.

6. Ziehr DR, Alladina J, Petri CR, Maley JH, Moskowitz A, Medoff BD, et al. Respiratory pathophysiology of mechanically ventilated patients with COVID-19: a cohort study. Am J Respir Crit Care Med. 2020; https://doi.org/ 10.1164/rccm.202004-1163LE.

\section{Publisher's Note}

Springer Nature remains neutral with regard to jurisdictional claims in published maps and institutional affiliations.

Ready to submit your research? Choose BMC and benefit from:

- fast, convenient online submission

- thorough peer review by experienced researchers in your field

- rapid publication on acceptance

- support for research data, including large and complex data types

- gold Open Access which fosters wider collaboration and increased citations

- maximum visibility for your research: over $100 \mathrm{M}$ website views per year

At $\mathrm{BMC}$, research is always in progress.

Learn more biomedcentral.com/submissions 